\title{
Reply to the Letter to the Editor
}

\section{Reply to the Letter to the Editor: Polyethylene Liner Dissociation is a Complication of the DePuy Pinnacle Cup: A Report of 23 Cases}

\author{
Emmanuel Koli MD
}

To the Editor,

appreciate the response of Drs. Bonilla and Bautista to our study, and their comments are well taken. The DePuy Pinnacle (Warsaw, IN, USA) acetabular cup and liner

(RE: Yun A, Koli EN, Moreland J, Iorio R,

Tilzey JF, Mesko JW, Lee GC, Froimson M. Polyethylene liner dissociation is a complication of the DePuy Pinnacle Cup: A report of 23 cases. Clin Orthop Relat Res. 2015;474:441-446).

The author certifies that he has no commercial associations (eg, consultancies, stock ownership, equity interest, patent/licensing arrangements, etc) that might pose a conflict of interest in connection with the submitted article.

All ICMJE Conflict of Interest Forms for authors and Clinical Orthopaedics and Related Research ${ }^{\circledR}$ editors and board members are on file with the publication and can be viewed on request.

The opinions expressed are those of the writers, and do not reflect the opinion or policy of $C O R R^{\mathbb{R}}$ or The Association of Bone and Joint Surgeons ${ }^{\circledR}$. construct does indeed have an excellent track record as they noted. However, the complication of liner dissociation is alarming. Since raising awareness in this article, our group has been alerted to anecdotal reports of 12 other liner failures. We hope this will be an ongoing discussion that can be addressed by surgeons and the implant manufacturer.
E. Koli MD ( $ه)$

Department of Orthopaedic Surgery and

Rehabilitation, Howard University

Hospital, 2041 Georgia Avenue NW,

Washington DC, USA

e-mail: emmanuelkoli@gmail.com 